LETTER TO JMG

\title{
Genotype and psychological phenotype in tuberous sclerosis
}

\author{
J C Lewis, H V Thomas, K C Murphy, J R Sampson
}

J Med Genet 2004;41:203-207. doi: 10.1136/jmg.2003.012757

T uberous sclerosis complex (TSC, MIM 191090 and 191100) is an autosomal dominant, multisystem disorder characterised by the development of a variety of hamartomatous growths. ${ }^{1}$ The TSC phenotype includes renal involvement (in over $80 \%$ of patients) with angiomyolipomas and cysts; skin involvement with facial angiofibromas, hypomelanotic macules, shagreen patches, and periungual fibromas; and cardiac, ophthalmic, and pulmonary involvement. Many of the frequent and serious complications of TSC, including epilepsy, mental retardation, and a wide range of psychiatric and behavioural disorders, reflect the cerebral involvement that occurs in over $90 \%$ of cases. Structural abnormalities in the brain include: cortical tubers that are localised areas of loss of normal hexalaminar cortical organisation, and that contain abnormal and enlarged cells categorised as cytomegalic neurones and balloon cells; subependymal nodules that are localised proliferations of abnormal cells in the periventricular zone; and migration tracts through the white matter linking subependymal and cortical lesions.

Mental retardation is estimated to occur in approximately $45 \%$ of cases. ${ }^{2}$ It is virtually always associated with a history of seizures correlated with early seizure onset, poor seizure control, and type of seizure at onset with the greatest risk for infantile spasms. ${ }^{3}$ The association between mental retardation and infantile spasms is particularly strong in the context of TSC. ${ }^{4}$ People with TSC are also reported to have high rates of autistic disorder, attention deficit hyperactivity disorder (ADHD), and sleep disorder. Although autistic disorder is a feature of several genetic disorders of childhood, its frequency is highest in $\mathrm{TSC}^{5}$ and the strength of the association does not appear to be explained simply by the frequency of infantile spasms in TSC. ${ }^{6}$ Sleep disorder in TSC is associated with the presence of other behavioural problems and can be exacerbated by nocturnal seizures. ${ }^{78}$ There are also anecdotal reports of anxiety disorder, psychosis, and mania in patients with TSC, ${ }^{6-13}$ but these phenotypes have not been subjected to systematic study.

Two genes causing TSC have been identified: TSC1 at chromosome $9 \mathrm{q} 34^{14}$, and TSC2 at $16 \mathrm{pl} 3.3 . .^{15}$ Their protein products hamartin (TSC1) and tuberin (TSC2) form a complex that regulates the PI3-kinase/AKT pathway to control cell size and proliferation. ${ }^{16-18}$ Loss of these cellular functions is likely to be central to the pathogenesis of hamartomas associated with TSC. Hamartin has also been shown to bind ezrin and to activate the small GTPase rho, so promoting changes in the cytoskeleton and cell adhesion. ${ }^{19}{ }^{20}$ Both TSC1 and TSC2 act as tumour suppressors, and somatic inactivation of the wild type allele through loss or intragenic mutation has been reported in many hamartomas associated with TSC. $^{21-23}$ However, a "two hit" mechanism of pathogenesis has not been established unequivocally in relation to cortical tubers. ${ }^{24}$

The relationship between genotype and phenotype in TSC has been the focus of a number of studies. A clear correlation has been established between polycystic kidney disease

\section{Key Points}

- Tuberous sclerosis complex (TSC, MIM 191090 and 191100 ) is an autosomal dominant disorder caused by mutations of the TSC1 and TSC2 genes. It is characterised by hamartomas in multiple organs, epilepsy, and psychological manifestations including mental retardation and autistic disorder.

- The psychological phenotypes of 92 unrelated index cases with characterised TSC1 and TSC2 mutations were assessed using validated measures of intellectual function, autistic disorder, anxiety, depression, and behavioural disorders.

- The presence of a TSC2 mutation was found to carry a higher risk of low IQ ( $p=0.0004)$, autistic disorder ( $p$ $=0.030)$, and infantile spasms $(p=0.001)$ than a TSC1 mutation. Cases with TSC2 mutations were also significantly more likely to have low $I Q$, after adjusting for history of infantile spasms by logistic regression analysis (OR $=3.50 ; 95 \% \mathrm{Cl}$ from 1.03 to 11.95 ).

- Previously unrecognised anxiety disorders were diagnosed in 20 of 36 adults with TSC who were capable of completing HADS assessment, and were frequent in cases with $\mathrm{TSC} 1$ and TSC2 mutations.

complicating TSC, and the presence of deletions involving both TSC2 and the immediately adjacent PKDI gene that is mutated in autosomal dominant polycystic kidney disease type $1 .^{25}$ Several studies have investigated aspects of disease severity in relation to TSC1 or TSC2 status. Jones et al ${ }^{26}$ noted that TSC1 mutations were under represented among sporadic but not familial cases with TSC. It was hypothesised that this might reflect less severe disease, on average, among cases with TSCI mutations. These cases would be more likely to reproduce, leading to ascertainment within the context of a positive family history; whereas mildly affected sporadic cases would be more likely to remain unascertained. Jones et al also established that intellectual handicap (assessed indirectly using existing medical records, reported special educational placement, or inability to live independently as an adult) was more frequent among TSC2 than TSC1 cases, supporting this hypothesis. ${ }^{27}$ Dabora $e t$ a ${ }^{28}$ undertook a more comprehensive survey of phenotypic manifestations, including cerebral, renal, and skin findings in 224 patients with TSC, 186 (83\%) of whom had characterised TSC1 (28) or TSC2 (158) mutations. Phenotypic data was extracted from patient records in several centres in the USA and Poland, using an instrument designed specifically for the study. TSCl cases were found to have a lower frequency of seizures, moderate to severe mental retardation, subependymal nodules, cortical tubers on imaging of the brain; and less severe renal and skin 
involvement. Two other studies have not identified significant phenotypic differences between TSC1 and TSC2 cases, but the power of one was limited by inclusion of only 38 patients, ${ }^{29}$ and the other did not undertake comprehensive mutation analysis at both loci. ${ }^{30}$

A consistent weakness in relation to psychiatric and behavioural aspects of TSC in previous studies of genotypephenotype correlation has been the use of non-validated tools to measure intellectual function and psychiatric and behavioural disorders. Furthermore, previous studies have not attempted to investigate the complex relationship between genotype, seizures, mental retardation, and behavioural phenotype. In the present study we have therefore addressed these issues in a cohort of 92 unrelated patients with TSC and characterised TSC1 or TSC2 mutations, using validated rating scales for the assessment of intellectual function and psychiatric and behavioural disorder.

\section{METHODS}

The study protocol was approved in November 1998 by the Multi Centre Research Ethics Committee for Wales and by the Local Research Ethics Committees with responsibility for each of the geographical locations in which patients were assessed.

\section{Subjects}

Subjects were recruited from a cohort of 157 unrelated index cases with TSC, who had been ascertained sequentially for molecular genetic research into TSC at the Institute of Medical Genetics, Cardiff. Cases ascertained were from adult and paediatric medical clinics, from regional genetics services, and learning disability services, with help from the Tuberous Sclerosis Association. All fulfilled the most recent criteria for definite clinical diagnosis of TSC. ${ }^{31}$ All had undergone comprehensive analysis for mutations at the TSC1 and TSC2 loci, using a range of methods for the detection of both small intraexonic and splice site mutations, and larger deletions and rearrangements. ${ }^{27}$

\section{Clinical assessments}

All subjects were assessed in their own homes or at a local genetics clinic by a single researcher (JCL), and their hospital medical records were reviewed. Assessments at interview included a structured clinical history detailing the onset, pattern of evolution, and treatment of seizures, and renal, skin, cardiac, and pulmonary symptoms; and a structured clinical examination. In addition, a range of standardised and validated psychological measures were used to assess intellectual level, autistic disorder, anxiety, depression, and behaviour. This involved:

- assessment of intellectual level using the Wechsler Adult Intelligence Scale (WAIS-R), ${ }^{32}$ Wechsler Intelligence Scale for Children (WISC-III), ${ }^{33}$ Raven's Coloured Progressive Matrices (RCPM), ${ }^{34}$ or Vineland Adaptive Behaviour Scale ${ }^{35}$

- assessment of autistic disorder using Childhood Autism Rating Scale (CARS) ${ }^{36}$

- assessment of problematic behaviours in children using Conner's Parent Rating Scale (CPRS) ${ }^{37}$

- Assessment of psychological symptoms using Strengths and Difficulties Scale, ${ }^{38}$ General Health Questionnaire, ${ }^{39}$ and Hospital Anxiety and Depression Scale (HADS). ${ }^{40}$

Statistical analysis was undertaken using the Statistical Package for the Social Sciences (SPSS) Version 10 for Windows. Chi squared $\left(\chi^{2}\right)$ tests examined the relationship between genotype and the variables of IQ $(<70 v \geqslant 70)$, autistic disorder, history of infantile spasms, anxiety disorder, and depression. Logistic regression analysis was employed in a multivariate analysis, taking low IQ as the outcome variable and genotype and infantile spasms as independent variables.

\section{RESULTS}

\section{Sample characteristics}

Of the original 157 participants, 11 had died since their original ascertainment, and a further 11 were living outside mainland UK. The 135 remaining subjects (or their carers) were approached by letter with an invitation to participate in the present study; 98 agreed (response rate 98/135 = 73\%), 9 declined, and 28 did not respond or could not be traced. Reanalysis of data on intellectual handicap reported by Jones et al $(1999)^{27}$ for subjects recruited to the present study compared with subjects who had either died, declined, or could not be traced, revealed no difference between the two groups $\left(\chi^{2}=0.155 ; \mathrm{df}=1 ; \mathrm{p}=0.690\right)$. Mutations had been characterised in 92 of the 98 recruited cases: 22 had TSC1 mutations (6 familial and 16 sporadic cases), and 70 had TSC2 mutations ( 5 familial cases, 64 sporadic cases, and one adopted case). The ages of participants at assessment for this study ranged from 6 to 70 years (mean 27 years; SD 14). TSC 1 cases were significantly older than TSC2 cases (means 33 years $v 25$ years, respectively; $\mathrm{t}=2.17 ; \mathrm{p}=0.038)$, consistent with their ascertainment at a greater age.

Of the 98 participants, 47 were male and 51 female. No gender difference was found for normal $v$ low IQ $\left(\chi^{2}=\right.$ $0.133 ; \mathrm{df}=1 ; \mathrm{p}=0.715)$, history of infantile spasms $\left(\chi^{2}=\right.$ $0.006 ; \mathrm{df}=1 ; \mathrm{p}=0.936)$, or autistic disorder $\left(\chi^{2}=0.022\right.$; $\mathrm{df}=1 ; \mathrm{p}=0.881)$. There was no gender difference between TSC1 and TSC2 probands $\left(\chi^{2}=0.915 ; \mathrm{df}=2 ; \mathrm{p}=0.633\right)$.

Of the 98 cases, 93 had a history of epilepsy, including all of those $(54 / 54)$ with an IQ of less than 70. Surprisingly, 20 of the $36(56 \%)$ adults who were able to complete the HADS had anxiety related scores of 8 or above, indicative of anxiety disorder, and seven (19\%) had depression related scores of 8 or above, indicative of depression. An apparent excess of these disorders in females did not reach significance $\left(\chi^{2}=\right.$ $0.1626 ; \mathrm{df}=1 ; \mathrm{p}=0.202 ;$ and $\chi^{2}=3.201 ; \mathrm{df}=1 ; \mathrm{p}=$ 0.074 , respectively).

Of the 98 cases, 86 were sporadic, 11 were familial, and one subject was adopted from biological parents of unknown genetic status. No significant differences in frequencies were found between familial index cases and sporadic cases for: low IQ (49/86 sporadic $v 4 / 11$ familial; $\chi^{2}=1.672 ; \mathrm{df}=1$; $\mathrm{p}=0.196)$, autistic disorder (30/86 sporadic $v 1 / 11$ familial; $\left.\chi^{2}=2.984 ; \mathrm{df}=1 ; \mathrm{p}=0.084\right)$, anxiety (17/30 sporadic $v 3 / 6$ familial; $\left.\chi^{2}=0.090 ; \mathrm{df}=1 ; \mathrm{p}=0.764\right)$, depression $\left(6 / 30\right.$ sporadic $v 1 / 6$ familial; $\left.\chi^{2}=0.035 ; \mathrm{df}=1 ; \mathrm{p}=0.851\right)$, or infantile spasms $\left(40 / 82\right.$ sporadic $v 2 / 11$ familial; $\chi^{2}=$ 3.667; df $=1 ; \mathrm{p}=0.056)$.

\section{Locus and phenotypic heterogeneity}

Phenotypic variables were considered as either present or absent. Intellectual level was categorised as either IQ of 70 or over, or IQ under 70. Intellectual level, history of infantile spasms, and presence of autistic disorder, anxiety, and depression were assessed in relation to TSC1 or TSC2 genotype. Low IQ, a history of autistic disorder, and infantile spasms were significantly more frequent in patients with TSC2 than TSC1 mutations (table 1). There was no significant difference between cases with TSC1 and TSC2 mutations in the frequency of current anxiety symptoms $(p=1.000)$, nor in the frequency of current depressive symptoms $(\mathrm{p}=$ $0.674)$.

Features of ADHD (assessed with the Conner's Parent Rating Scale) and problem behaviours in children (assessed 
Table 1 Intellectual level, autistic disorder, and infantile spasms in cases with characterised TSC1 and TSC2 mutations

\begin{tabular}{|c|c|c|c|c|c|}
\hline Characteristic & Total number & $\mathrm{TSCl}$ & TSC2 & $\chi^{2}$ & $\mathbf{p}$ \\
\hline $\begin{array}{l}1 Q \geqslant 70 \text { (all } \\
\text { cases)* }\end{array}$ & 41 & $17(77 \%)$ & $24(34 \%)$ & 12.5 & $<0.001$ \\
\hline $\begin{array}{l}1 \mathrm{Q}<70 \text { (all } \\
\text { cases) }\end{array}$ & 51 & $5(23 \%)$ & $46(66 \%)$ & & \\
\hline $\begin{array}{l}1 Q \geqslant 70 \\
\text { (sporadics)t }\end{array}$ & 34 & $11(69 \%)$ & $23(36 \%)$ & 5.6 & 0.018 \\
\hline $\begin{array}{l}\mid Q<70 \\
\text { (sporadics)t }\end{array}$ & 46 & $5(31 \%)$ & $41(64 \%)$ & & \\
\hline $\begin{array}{l}\text { No autistic } \\
\text { disorder (all } \\
\text { cases)* }\end{array}$ & 62 & $19(86 \%)$ & $43(61 \%)$ & 4.74 & 0.030 \\
\hline $\begin{array}{l}\text { Autistic } \\
\text { disorder (all } \\
\text { cases)* }\end{array}$ & 30 & $3(14 \%)$ & $27(39 \%)$ & & \\
\hline $\begin{array}{l}\text { No autistic } \\
\text { disorder } \\
\text { (sporadics)† }\end{array}$ & 52 & $13(81 \%)$ & 39 (61\%) & 2.32 & 0.128 \\
\hline $\begin{array}{l}\text { Autistic } \\
\text { disorder } \\
\text { (sporadics)t }\end{array}$ & 28 & $3(19 \%)$ & 25 (39\%) & & \\
\hline $\begin{array}{l}\text { No IS (all } \\
\text { cases) }\end{array}$ & 44 & $16(84 \%)$ & $28(42 \%)$ & 10.32 & 0.001 \\
\hline IS (all cases)* & 41 & $3(16 \%)$ & $38(58 \%)$ & & \\
\hline $\begin{array}{l}\text { No IS } \\
\text { (sporadics)t }\end{array}$ & 35 & $10(77 \%)$ & 25 (42\%) & 5.32 & 0.021 \\
\hline IS (sporadics)t & 38 & $3(23 \%)$ & $35(58 \%)$ & & \\
\hline
\end{tabular}

with the Strengths and Difficulties Scale) were not analysed in relation to TSCl and TSC2 status, because only two participants under the age of 16 years had TSC1 mutations.

Both the presence of a TSC2 mutation, in comparison with the presence of a TSCl mutation, and a history of infantile spasms significantly increased the likelihood of low IQ as an outcome (table 2). In view of the significant correlation between presence of a TSC2 mutation and a history of infantile spasms (table 1), logistic regression analysis was performed to examine further the relationship between genotype, history of infantile spasms, and IQ. The presence of a TSC2 mutation and infantile spasms were significant independent determinants of low IQ (table 2), with infantile spasms being most strongly associated with low IQ.

Both the presence of a TSC2 mutation, in comparison with the presence of a TSC1 mutation, and a history of infantile spasms as an outcome significantly increased the likelihood of low IQ (unadjusted rows in table 2). In view of the significant correlation between the presence of a TSC2 mutation and a history of infantile spasms (table 1), logistic regression analysis was performed to examine further the relationship between genotype, history of infantile spasms, and IQ, revealing that increased risk of low IQ could also be attributed independently to the presence of a TSC2 mutation and a history of infantile spasms (adjusted rows in table 2 ).

Table 2 Logistic regression analysis of 78 cases, taking $I Q$ less than 70 as outcome variable

\begin{tabular}{lllc}
\hline Determinant & Odds ratio & $95 \% \mathbf{C l}$ & $\mathbf{p}$ \\
\hline TSC2 (unadjusted) & 6.52 & $2.14-19.83$ & 0.001 \\
TSC2 (adjusted) & 3.50 & $1.03-11.95$ & 0.045 \\
IS (unadjusted) & 9.71 & $3.53-26.69$ & $<0.0005$ \\
IS (adjusted) & 7.37 & $2.59-21.00$ & $<0.0005$ \\
\hline \multicolumn{2}{l}{ Cl, confidence interval; IS, infantile spasms. }
\end{tabular}

\section{Mutation class and position, and phenotypic heterogeneity}

The exact nature and location of mutations had been defined in 92 cases. These comprised a total of 81 different mutations, because six TSC2 mutations were shared by at least two individuals. Phenotypes varied between unrelated individuals sharing identical TSC2 mutations. A much larger series would be required to establish whether this variation was less marked than that seen between patients with different TSC2 mutations. Investigation of subgroups of subjects showing the most and least severe phenotypes, assessed where possible using quantitative measures (as we did here), might help in addressing this question.

All but one of the TSC1 mutations (an in frame deletion) was predicted to be truncating. Cases with TSC2 mutations included 53 with mutations that were predicted to be truncating and 17 with mutations that were predicted to be non-truncating. No significant difference was seen in the frequency of low IQ $\left(\chi^{2}=0.237 ; \mathrm{df}=1 ; \mathrm{p}=0.627\right)$, autistic disorder $\left(\chi^{2}=0.064 ; \mathrm{df}=1 ; \mathrm{p}=0.800\right)$, or infantile spasms $\left(\chi^{2}=0.060 ; \mathrm{df}=2 ; \mathrm{p}=0.970\right)$ in cases with truncating as opposed to non-truncating TSC2 mutations in which less severe effects on protein function might be anticipated (table 3). Neither did analysis of the nucleotide position of truncating TSC2 mutations (considered as non-parametric continuous variables), using the MannWhitney U test, reveal a significant relationship with low IQ, autistic disorder, or infantile spasms (there were insufficient numbers of TSCI cases for comparable analysis of mutations at that locus).

\section{DISCUSSION}

In this study we found that people with TSC2 mutations were significantly more likely than those with TSCl mutations to have autistic disorder, a low IQ, and a history of infantile spasms. In addition, low IQ was found to be independently associated with both TSC2 mutations and a history of infantile spasms.

Participants in the current study were ascertained from a variety of clinical settings, and are likely to be broadly representative of unrelated index cases with TSC who come to medical attention. The frequency of medical, psychiatric, and behavioural disorders in this group is expected to be higher than in epidemiological samples of patients with TSC that include secondarily ascertained members of multiplex families, in whom milder disease might be anticipated. Also, our sample is biased towards sporadic rather than familial cases when compared with other large series. ${ }^{28}$ This probably reflects our efforts to recruit sporadic cases in particular to the present study.

In this study, $55 \%$ of cases had an IQ of less than 70 , compared with $44.5 \%$ in a recent epidemiological survey ${ }^{2}$;

Table 3 Low $I Q$, autistic disorder, and infantile spasms in TSC2 cases with truncating and non-truncating mutations

\begin{tabular}{|c|c|c|c|c|c|}
\hline $\begin{array}{l}\text { Clinical } \\
\text { feature }\end{array}$ & $\begin{array}{l}\text { Total } \\
\text { cases }\end{array}$ & $\begin{array}{l}\text { Truncating, } \\
53 \text { cases }\end{array}$ & $\begin{array}{l}\text { Non- } \\
\text { truncating, } \\
17 \text { cases }\end{array}$ & $\chi^{2}$ & $p$ \\
\hline $\mid Q> \pm 70$ & 24 & $19(36 \%)$ & $5(29 \%)$ & 0.237 & 0.627 \\
\hline $\mathrm{IQ}<\overline{\overline{70}}$ & 46 & $34(64 \%)$ & $12(71 \%)$ & & \\
\hline $\begin{array}{l}\text { No autistic } \\
\text { disorder }\end{array}$ & 43 & $33(62 \%)$ & $10(59 \%)$ & 0.064 & 0.800 \\
\hline $\begin{array}{l}\text { Autistic } \\
\text { disorder }\end{array}$ & 27 & $20(38 \%)$ & $7(41 \%)$ & & \\
\hline No IS & 29 & $22(45 \%)$ & $7(44 \%)$ & 0.060 & 0.970 \\
\hline IS & 36 & $27(55 \%)$ & $9(56 \%)$ & & \\
\hline
\end{tabular}


and $95 \%$ had a history of seizures, compared with $79 \%$ in the epidemiological sample. These differences are likely to reflect the medical ascertainment sources in the current study and the inclusion of probands only. In the present study, 33\% of subjects were found to have autistic disorder, as assessed by the Childhood Autistic Disorder Rating Scale (CARS).${ }^{36}$ CARS is based on Kanner's criteria ${ }^{41}$ for the diagnosis of autistic disorder, and not on the wider diagnostic category of pervasive developmental disorder. Previous estimates of the frequency of autistic disorder in TSC have varied, not only because of different modes of ascertainment, but also because of differences in the diagnostic criteria that have been employed, including DSM III- ${ }^{42}$ and ICD- $10{ }^{43}$ Hunt and Shepherd ${ }^{44}$ identified autistic disorder in 5/21 (24\%) of TSC cases ascertained through hospital departments and the Tuberous Sclerosis Association (a UK patient support group); whereas Gillberg et $a l^{42}$ diagnosed autistic disorder in 17/28 $(61 \%)$ of patients under 20 years of age, identified in a population based study.

Although anxiety and depression are common complications of chronic illnesses in general, ${ }^{45}{ }^{46}$ it was noteworthy that $20 / 36(56 \%)$ of adults capable of completing the HADS assessments scored above the threshold indicative of anxiety disorder. Anxiety disorders appeared to be under recognised in TSC, because none of the patients involved had received advice or treatment for these disorders, perhaps owing to the frequent comorbid effects of autism and intellectual handicap.

\section{Locus and phenotype heterogeneity}

TSC2 mutations (70/92, 76\%) were more frequent than TSC1 mutations $(21 / 92,24 \%)$ in our series, and the proportions were very similar to those reported by Dabora $e^{2} \mathrm{al}^{28}$ in a large independent series of medically ascertained people with TSC. Our finding, that TSC2 mutations are more frequently associated with low IQ, infantile spasms, and autistic disorder than are TSC1 mutations, is consistent with two previous studies that suggested greater severity in disease determined by TSC2 than in disease determined by TSC1. ${ }^{27} 28$ It is currently unclear whether the increased risk of low IQ and autistic disorder in persons with TSC2 mutations is mediated by an increased risk of infantile spasms alone, but our data suggest some independence of genotype and infantile spasms as risk factors. This issue is of great significance to the potential for therapeutic intervention in TSC. An experimental approach to resolving the question would be a randomised trial of pre-emptive antiepileptic drug medication in cases of TSC diagnosed antenatally. Detection of cardiac rhabdomyomas on routine antenatal ultrasound would now make such a trial technically feasible. Unfortunately, symptomatic CNS manifestations have not been noted in single locus knockout animal models of TSC, so precluding preclinical trials to address this issue. It is of interest, however, that murine Tsc2 mutations do appear to be associated with a more severe visceral phenotype than Tscl mutations on the same genetic background. ${ }^{47}$

Since the TSC1 and TSC2 gene products, hamartin and tuberin, have been shown to form a functional complex ${ }^{30} 4849$ that acts to suppress cell growth via the PI3-kinase/AKT pathway, ${ }^{50} 51$ it may not be immediately apparent why severity of disease determined by TCSI should differ from that determined by TCS2. One possibility is that the somatic mutation rate is higher at the TSC2 locus, leading to more frequent "second hit" mutations and hence more frequent development of hamartomas. However, it remains unclear whether all the CNS manifestations of TSC result from a "two hit" mechanism. Careful molecular genetic studies of cortical tubers, including laser capture microdissection of cytomegalic neurones in one study, have failed to identify somatic "second hit" mutations in tubers, in contrast to a variety of visceral hamartomas. ${ }^{23}{ }^{24}$ Alternatively, or in addition, tuberin may have currently unidentified roles that are not shared by hamartin.

The increasing evidence for severity differences between disease determined by TSC1 and TSC 2 presents issues for those involved in discussing prognosis for TSC that is diagnosed antenatally or in early childhood. However, the great range of phenotypic severity seen among unrelated persons sharing identical mutations, and even among different affected members of large families, will continue to demand a cautious approach. Further genetic studies are likely to identify loci that modify the phenotypic effects of TSC1 and TSC2 mutations, and clinical studies have the potential to clarify the extent to which long term outcomes can be modified by early (or possibly pre-emptive) treatment with antiepileptic drugs. Clarification of the roles of TSCI and TSC2 in regulating cell growth through the P13-kinase/AKT pathway ${ }^{42}{ }^{43}$ has identified inhibitors of this pathway, such as rapamycin, as potential therapies when either gene is mutated.

\section{ACKNOWLEDGEMENTS}

We thank the patients and their families who contributed to this study. Ann Hunt and Professor Patrick Bolton provided invaluable help with recruitment and research methodology.

We are grateful to the Tuberous Sclerosis Association (UK) for funding to JCL, and to the Tuberous Sclerosis Alliance for funding to develop genotyping.

\section{Authors' affiliations}

J C Lewis, J R Sampson, Institute of Medical Genetics, University of Wales College of Medicine, Cardiff, UK

H V Thomas, Department of Psychological Medicine, University of Wales College of Medicine, Cardiff, UK

K C Murphy, Department of Psychiatry, Royal College of Surgeons in Ireland, Beaumont Hospital, Dublin, Eire

J R Sampson, Institute of Medical Genetics, University of Wales College of Medicine, Cardiff, UK

Correspondence to: J R Sampson, Institute of Medical Genetics, University of Wales College of Medicine, Heath Park, Cardiff CF14 4N, UK; sampson @cf.ac.uk

Received 23 July 2003

Accepted 24 October 2003

\section{REFERENCES}

1 Gomez MR, Sampson JR, Holets Whittemore V, eds. Tuberous sclerosis complex. 3rd edn. New York: Oxford University Press, 1999:10-22.

2 Joinson C, O'Callaghan FJ, Osborne JP, Martyn C, Harris T, Bolton PF. Learning disability and epilepsy in an epidemiological sample of individuals with tuberous sclerosis complex. Psychol Med 2003;33:335-44.

3 Webb DW, Fryer AE, Osborne JP. Morbidity associated with tuberous sclerosis: a population study. Dev Med Child Neurol 1996;38:146-55.

4 Riikonen R, Simell O. Tuberous sclerosis and infantile spasms. Dev Med Child Neurol 1990;32:203-9

5 Gillberg C. Subgroups in autistic disorder: are there behavioural phenotypes typical of underlying medical conditions? J Intellect Disabil Res 1992;36:201-14.

6 Hunt A, Dennis J. Psychiatric disorder among children with tuberous sclerosis. Dev Med Child Neurol 1987;29:190-8.

7 Hunt A. Development, behaviour and seizures in 300 cases of tuberous sclerosis. J Intellect Disabil Res 1993;37:41-51.

8 Bruni O, Cortesi F, Giannotti F, Curatolo P. Sleep disorders in tuberous sclerosis: a polysomnographic study. Brain Dev 1995;17:52-6.

9 Smalley SL, Burger F, Smith M. Phenotypic variation of tuberous sclerosis in a single extended kindred. J Med Genet 1994;31:761-5.

10 Zlotlow M, Kleiner S. Catatonic schizophrenia associated with tuberous sclerosis. Psychiatr Q 1965;39:466-75.

11 Clarke D, Buckley ME, Burns BH. Epilepsy and psychosis - ask the family. Br J Psychiatry 1987; 150:702-3.

12 Holschneider DP, Szuba MP. Capgras syndrome and psychosis in a patient with tuberous sclerosis. J Neuropsychiatry Clin Neurosci 1992;4:353.

13 Khanna R, Borde M. Mania in a five-year-old child with tuberous sclerosis. Br J Psychiatry 1989;155:117-19. 
14 The TSCl Consortium. Identification of the tuberous sclerosis gene TSCl on chromosome 9q34. Science 1997;277:805-8.

15 The European Chromosome 16 Tuberous Sclerosis Consortium. Identification and characterization of the tuberous sclerosis gene on chromosome 16. Cell 1993;75:1305-15.

16 Gao, Pan D. TSC1 and TSC2 tumor suppressors antagonize insulin signaling in cell growth. Genes Dev 2001;15:1383-92.

17 Inoki K, Li Y, Zhu T, Wu J, Guan KL. TSC2 is phosphorylated and inhibited by Akt and suppresses mTOR signalling. Nat Cell Biol 2002;4:648-57.

18 McManus EJ, Alessi DR. TSC1-TSC2: a complex tale of PKB-mediated S6K regulation. Nat Cell Biol 2002;4:E214-16.

19 Lamb RF, Roy C, Diefenbach TJ, Vinters HV Johnson MW, Jay DG, Hall A The TSC1 tumour suppressor hamartin regulates cell adhesion through ERM proteins and the GTPase Rho. Nat Cell Biol 2000;2:281-7.

20 Astrinidis A, Cash TP, Hunter DS, Walker CL, Chernoff J, Henske EP. Tuberin the tuberous sclerosis complex 2 tumor suppressor gene product, regulates Rho activation, cell adhesion and migration. Oncogene 2002;2:8470-6.

21 Green A, Johnson P, Yates J. The tuberous sclerosis gene on chromosome 9q34 acts as a growth suppressor. Hum Mol Genet 1994;3:1833-4.

22 Carbonara C, Longa L, Grosso E, Borrone C, Garre MG, Brisigotti M, Migone N. 9q34 loss of heterozygosity in a tuberous sclerosis astrocytoma suggests a growth suppressor-like activity also for the $\mathrm{TSCl}$ gene. Hum Mol Genet 1994;3:1829-32.

23 Henske EP, Scheithauer BW, Short MP, Wollmann R, Nahmias J, Hornigold N, van Slegtenhorst M, Welsh CT, Kwiatkowski DJ. Allelic loss is frequent in tuberous sclerosis kidney lesions but rare in brain lesions. Am J Hum Genet 1996;59:400-6

24 Niida $Y$, Stemmer-Rachamimov AO, Logrip M, Tapon D, Perez R, Kwiatkowski DJ, Sims K, MacCollin M, Louis DN, Ramesh V. Survey of somatic mutations in tuberous sclerosis complex (TSC) hamartomas suggests different genetic mechanisms for pathogenesis of TSC lesions. Am J Hum Genet 2001;69:493-503.

25 Sampson JR, Maheshwar MM, Aspinwall R, Thompson P, Cheadle JP, Ravine D, Roy S, Haan E, Bernstein J, Harris PC. Renal cystic disease in tuberous sclerosis: role of the polycystic kidney disease 1 gene. Am J Hum Genet 1997;61:843-51.

26 Jones AC, Daniells CE, Snell RG, Tachataki M, Idziaszczyk SA, Krawczak M Sampson JR, Cheadle JP. Molecular genetic and phenotypic analysis reveals differences between TSC1 and TSC2 associated familial and sporadic tuberous sclerosis. Hum Mol Genet 1997;6:2155-61.

27 Jones AC, Shyamsundar MM, Thomas MW, Maynard J, Idziasczyk S, Tomkins S, Sampson JR. Comprehensive mutation analysis of TSC1 and TSC2 - and phenotypic correlations in 150 families with tuberous sclerosis. Am J Hum Genet 1999;64:1305-15.

28 Dabora SL, Jozwiak S, Franz DN, Roberts PS, Nieto A, Chung J, Choy Y, Reeve MP, Thiele E, Egelhoff JC, Kasprzyk-Obara J Domanska-Pakiela D, Kwiatkowski DJ. Mutational analysis in a cohort of 224 tuberous sclerosis patients indicates increased severity of TSC2 compared with TSC1 disease in multiple organs. Am J Hum Genet 2001;68:64-80.

29 Zhang H, Nanba E, Yamamoto T, Ninomiya H, Ohno K, Mizuguchi M Takeshita K. Mutational analysis of TSC1 and TSC2 genes in Japanese patients with tuberous sclerosis complex. J Hum Genet 1999;44:391-6.

30 van Slegtenhorst M, Verhoef S, Tempelaars A, Bakker L, Wang Q, Wessels M Bakker R, Nellist M, Lindhout D, Halley D, van den Ouweland A. Mutationa spectrum of the TSC1 gene in a cohort of 225 tuberous sclerosis complex patients: no evidence for genotype-phenotype correlation. J Med Genet 1999;36:285-9.

31 Roach ES, Gomez MR, Northrup H. Tuberous sclerosis complex consensus conference: revised clinical diagnostic criteria. J Child Neurol 1998;13:624-8

32 Wechsler adult intelligence scale - revised. London: Psychological Corporation, 1981.

33 Wechsler intelligence scale for children - III. London: Psychological Corporation, 1992.

34 Raven J, Raven JC, Court JH. Coloured progressive matrices. Oxford: Oxford Psychologists Press, 1998.

35 Sparrow SS, Balla DA, Cicchetti DV. Vineland adaptive behaviour scales. American Guidance Service. Minnesota, USA: Circle press, 1984

36 Schopler E, Reichler RJ, DeVellis RF, Daly K. Toward objective classification of childhood autistic disorder: Childhood Autistic Disorder Rating Scale (CARS). J Autism Dev Disord 1980;10:91-103.

37 Conners CK. Conner's Rating Scales-Revised. New York: Multi-Health Systems, 1997.

38 Goodman R. The Strengths and Difficulties Questionnaire: a research note. Journal Child Psychol Psychiatry 1997;38:581-6.

39 Goldberg $\mathbf{D}$. The detection of psychiatric illness by questionnaire. London: Oxford University Press, 1972

40 Zigmond AS, Snaith RP. The Hospital Anxiety and Depression Scale. Acta Psychiatr Scand 1983;67:361-70.

41 Kanner L. Autistic disturbances of affective contact. J Pediatr 1943;2:217-50.

42 Gillberg IC, Gillberg C, Ahlsén G. Autistic behaviour and attention deficits in tuberous sclerosis: a population-based study. Dev Med Child Neurol 1994;36:50-6

43 Smalley SL, Tanguay PE, Smith M, Gutierrez G. Autistic disorder and tuberous sclerosis. J Autism Dev Disord 1992;22:339-56.

44 Hunt A, Shepherd C. A prevalence study of autistic disorder in tuberous sclerosis. J Autism Dev Disord 1993:23:323-39.

45 Friedman S, Vila G, Timsit J, Boitard C, Mouren-Simeoni MC. Anxiety and depressive disorders in an adult insulin-dependent diabetic mellitus (IDDM) population: relationships with glycaemic control and somatic complications. Eur Psychiatry 1998;13:295-302.

46 O'Donoghue MF, Goodridge DM, Redhead K, Sander JW, Duncan JS Assessing the psychosocial consequences of epilepsy: a community-based study. Br J Gen Pract 1999;49:211-14

47 Kwiatkowski DJ, Zhang H, Bandura JL, Heiberger KM, Glogauer M, elHashemite $\mathrm{N}$, Onda $\mathrm{H}$. A mouse model of TSCl reveals sex-dependent lethality from liver hemangiomas, and up-regulation of p70S6 kinase activity in Tscl null cells. Hum Mol Genet 2002;11:525-34.

48 Hodges AK, Li S, Maynard J, Parry L, Braverman R, Cheadle JP, De Clue JE, Sampson J. Pathological mutations in TSC1 and TSC2 disrupt the interaction between hamartin and tuberin. Hum Mol Genet 2001;10:2899-905.

49 Plank TL, Yeung RS, Henske EP. Hamartin, the product of the tuberous sclerosis 1 (TSC1) gene, interacts with tuberin and appears to be localized to cytoplasmic vesicles. Cancer Res 1998;58:4766-770.

50 Potter $\mathrm{CJ}$, Huang $\mathrm{H}, \mathrm{Xu}$. Drosophila $T s c 1$ functions with $T s c 2$ to antagonize insulin signaling in regulating cell growth, cell proliferation, and organ size. Cell 2001; 105:357-68

51 Tee AR, Fingar DC, Manning BD, Kwaitkowski DJ, Cantley LC, Blenis J. Tuberous sclerosis complex-1 and -2 gene products function together to inhibit mammalian target of rapamycin (mTOR)-mediated downstream signaling. Proc Natl Acad Sci U S A 2002;99:13571-6. 